УДК 681.5

\author{
ЖУЧЕНКО Л. К. \\ Національний технічний університет України \\ «Київський політехнічний інститут імені Ігоря Сікорського»

\section{ВІДМОВОСТІЙКА СИСТЕМА КЕРУВАННЯ ПРОЦЕСОМ ФОРМУВАННЯ ВУГЛЕЦЕВИХ ВИРОБІВ}

У статті розроблений метод синтезу відмовостійкої системи керування ииклічним процесом формування вуглецевих виробів, яка враховує похибки керування, ще виникають із-за несправностей регулювальних органів в умовах дії невідомих збурень. 3 урахуванням ичиклічності технологічного процесу, що розглядається, при синтезі системи керування використаний метод керування з ітераційним навчанням. Даний метод розглядає ичиклічні процеси на основі 2-вимірної моделі (2D-модель). Запропонований алгоритм керування гарантує збіжність процесу керування до завдання яку часі, так і на кожному цииклі роботи для того, щоб забезпечити потрібну якість керування навіть в умовах дї невідомих збурень та похибок у реалізації керування регулювальними органами. Синтез системи керування здійснюється на основі розв 'язання системи лінійних матричних нерівностей.

Ключові слова: відмовостійка система, вуглецеві вироби, керування, алгоритм керування, якість керування.

\title{
DOI: 10.20535/2617-9741.4.2021.248878
}

Corresponding author: zhuch.1.k89@ukr.net

Received 21 July 2021; Accepted 30 August 2021

Постановка проблеми. Сучасні світові тенденції розвитку чорної та кольорової металургії, машинобудування, хімічної промисловості та інших галузей промисловості обумовлюють постійне нарощування обсягів виробництва графітованих вуглецевих виробів. Графіт широко використовується як футеровочний матеріал в доменних та феросплавних печах, атомній промисловості, є незамінним в електротермії. Значним споживачем графітованих виробів є алюмінієве виробництво.

Виробництво вуглецевих виробів $\epsilon$ у значній мірі ресурсо- та енергозатратним [1,2]. Саме тому підвищення ефективності даного виробництва $є$ актуальним науково-практичним завданням, особливо в сучасних умовах постійного зростання вартості енергоносіїв. Ефективним способом розв'язання даного завдання $є$ створення сучасної системи керування технологічним процесом з урахуванням можливих відмов елементів системи.

Одним з основних технологічних процесів виробництва вуглецевих виробів $є$ формування вуглецевих виробів, адже саме на етапі пресування електродних заготовок закладаються в основному всі спадкові властивості, що визначають якість готових виробів [3-5]. Зокрема, пресування в значній мірі визначає форму заготовки, ії довжину, пористість та механічну міцність.

Формування виробів здійснюється у гідравлічних пресах одним з двох способів: 1) формуванням в закриту матрицю, 2) продавлюванням через мундштук відповідної форми. Проте спосіб з продавлюванням через мундштук має ряд переваг, він найчастіше використовується у виробництві, тому саме цей спосіб формування вуглецевих виробів розглядається у даному дослідженні.

Процес формування вуглецевих виробів складається з 3-х стадій $[1,3,6]$ : завантаження, пресування та охолодження. На стадії завантаження особливу роль відіграє швидкість пресування [1,3-6], чим і обумовлюється актуальність створення ефективної системи керування нею. Як свідчить практика експлуатації гідравлічних пресів у вуглеграфітовому виробництві $[4,5]$, регулювальний клапан гідравлічного пресу іноді виходить з ладу або працює з похибками. Саме тому у даній роботі розглядається стадія завантаження процесу формування вуглецевих виробів з точки зору побудови відмовостійкої системи керування швидкістю пресування.

Аналіз попередніх досліджень. Докладний аналіз існуючих систем керування процесом формування вуглецевих виробів проведений у працях $[1,3]$. На жаль, у згаданих працях не розглядаються питання побудови відмовостійкої системи керування.

Питанням створення відмовостійких систем керування приділена велика увага у дослідженнях зарубіжних фахівців.

(C) The Author(s) 2021. Published by Igor Sikorsky Kyiv Polytechnic Institute.This is an Open Access article distributed under the terms of the license CC BY 4.0 (https://creativecommons.org/licenses/by/4.0/), which permits re-use, distribution, and reproduction in any medium, provided the original work is properly cited. 
Сучасні вимоги до підвищення ефективності виробництва формують повні виклики до систем керування технологічними процесами в умовах відмов елементів систем. Керування технологічними процесами, як правило, базується на великій кількості вимірювань, яке реалізується відповідними регулювальними органами. Якщо несправність останніх не виявлена своєчасно з відповідними коригувальними діями, то це може призвести до нерегламентного режиму роботи, а у крайньому випадку до проблем з безпекою людей та обладнання.

Системи діагностування відмов (СДВ) повинні визначати місце знаходження відмови та оцінювати іiі характеристики, а відмовостійкість системи (ВСС) керування мають забезпечувати функціонування об’єктів керування прийнятному режимі в умовах присутності відмов. У зв'язку з цим останніми роками СДВ та ВСС набули особливої уваги дослідників [7-12].

На жаль, більшість відомих досліджень у цьому напрямку пов'язані з неперервними процесами, не зважаючи на широке розповсюдження циклічних процесів у хімічній, харчовій, переробній та інших галузях промисловості. До циклічних технологічних процесів відноситься і процес формування вуглецевих виробів.

Деякі автори розглядають циклічні процеси як послідовність неперервних [13]. Але при цьому виникають два питання . Перше, тільки асимптотична поведінка замкненої системи розглядається при проєктуванні так званої традиційної ВСС(ТВСС). Враховуючи, що належний цикл циклічного процесу триває кінцевий час, для досягнення бажаного результату керування може не вистачити часу. Друге, при ТВСС процес керування не використовує досвід попередніх циклів i, отже, черговий цикл не може бути покращений на підставі набутого досвіду.

У той же час високу ефективність при керуванні циклічними процесами продемонстрував метод керування 3 ітераційним навчанням (КIH). У праці [14] робастне КІН застосовується для керування процесом екструзії 3 невідомими початковими умовами та збуреннями при умові відстеження довільно обмеженого завдання.

Синтез та аналіз КІН у частотній області представлений у [15].

У праці [16] розглядається КІН - стратегія для керування якістю кінцевої продукції. Циклічний процес у даному дослідженні моделюється як двовимірна (2D) система і синтез робастної КІН формулюється як задача робастної стабілізації $2 \mathrm{D}$ - системи.

Метою статті $є$ синтез методу побудови відмовостійкої системи керування циклічним процесом формування вуглецевих виробів, що забезпечує прийнятне функціонування об’єкту керування у нештатних умовах.

Процес формування вуглецевих виробів як циклічний процес математично у загальному вигляді у просторі станів може бути описаний таким чином:

$$
\left\{\begin{array}{l}
x(t+1, k)=A x(t, k)+B u(t, k)+w(t, k) \\
y(t, k)=C x(t, k)
\end{array}\right\},
$$

для $x(0, k)=x_{0, k} ; t=0,1, \ldots, T ; k=1,2, \ldots$, де $t$ - час, $k$ - номер циклу (ітерації), $x_{0, k}$ - початковий стан системи на $k$ - й ітерації (враховуючи, що початковий стан на кожній ітерації практично один і той самий, будемо вважати, що $\left.x_{0, k} \equiv x_{0}\right)$. Крім того, $x(t, k) \in \mathbb{R}^{n}, y(t, k) \in \mathbb{R}^{l}$ і $u(t, k)=\left[u_{1}(t, k), u_{2}(t, k), \ldots, u_{m}(t, k)\right]^{T}$ представляють відповідно змінні стану, вихідні змінні та керування у часі $t$ на $k$-й ітерації. Величина $w(t, k)$ - збурення як результат неточності моделі процесу та дії зовнішніх збурень. Матриці А,В та С - матриці відповідної вимірності.

Якщо керувальна змінна $u_{i}(t, k)(i=1,2, \ldots, \mathrm{m})$ реалізується виконавчим пристроєм 3 похибкою, що призводить до значення керувальної змінної $u_{i}^{\delta}(t, k)$, запишемо :

$$
\left.u_{i}^{\delta}(t, k)=\alpha_{i} u_{i}(t, k) \quad \text { (для } i=1,2, \ldots, m\right),
$$

де

$$
\left.0 \leq \alpha_{i_{u}} \leq \alpha_{i} \leq \alpha_{i}^{B} \quad \text { (для } i=1,2, \ldots, m\right) .
$$

Величини $\alpha_{i_{u}}\left(\alpha_{i_{u}} \leq 1\right)$ та $\alpha_{i}^{\beta}\left(\alpha_{i}^{\beta} \geq 1\right)$ - відомі скалярні величини.

Модель (2) для урахування несправностей широко використовується при синтезі ВСС-керування $[17,18]$. Параметр $\alpha_{i}$ невідомий, але припускається, що він змінюється у відомому діапазоні. Випадок, коли $\alpha_{i_{n}}=\alpha_{i}^{\beta}$, означає відсутність несправностей і $u_{i}^{\delta}=u_{i}$. Випадок, коли $\alpha_{i}=0$, відповідає повній несправності. Якщо $\alpha_{i}>0$, то має місце часткова несправність. 
Позначимо

$$
\begin{gathered}
u^{\delta}=\left[u_{1}^{\delta}, u_{2}^{\delta}, \ldots, u_{m}^{\delta}\right]^{T} \\
\alpha^{B}=\operatorname{diag}\left[\alpha_{1}^{B}, \alpha_{2}^{B}, \ldots, \alpha_{m}^{B}\right], \\
\alpha_{H}=\operatorname{diag}\left[\alpha_{1_{\mu}}, \alpha_{2_{H}}, \ldots, \alpha_{m}\right], \\
\alpha=\operatorname{diag}\left[\alpha_{1}, \alpha_{2}, \ldots, \alpha_{m}\right] .
\end{gathered}
$$

Тоді циклічний процес формування вуглецевих виробів в умовах несправностей регулювальних органів математично описується такими рівняннями:

$$
\left\{\begin{array}{l}
x(t+1, k)=A x(t, k)+B \alpha u(t, k)+w(t, k) \\
y(t, k)=C x(t, k)
\end{array}\right\} .
$$

Мета керування полягає у визначенні такого закону керування, при якому вихідні змінні процесу максимально наближено відслідковують задану траєкторію руху системи $y_{r}(t)$ навіть при наявності несправностей регулювальних органів. Розробити структуру та методи синтезу системи керування, яка б забезпечувала виконання поставленої мети з урахуванням циклічності процесу формування вуглецевих виробів і $є$ завданням даного дослідження.

\section{Традиційна відмовостійка система керування (ТВСС-керування)}

Під ТВСС-керуванням будемо розуміти відмовостійку систему керування без урахування циклічності процесу формування вуглецевих виробів.

Похибка керування визначається таким чином

$$
e(t, k)=y_{r}(t)-y(t, k)
$$

Введемо такі позначення

$$
\begin{gathered}
\beta=\operatorname{diag}\left[\beta_{1}, \beta_{2}, \ldots, \beta_{m}\right], \\
\beta_{0}=\operatorname{diag}\left[\beta_{10}, \beta_{20}, \ldots, \beta_{m 0}\right],
\end{gathered}
$$

при чому

$$
\begin{gathered}
\beta_{i}=\frac{\alpha_{i}^{B}+\alpha_{i_{u}}}{2}(\text { для } i=1,2, \ldots, m), \\
\beta_{i 0}=\frac{\alpha_{i}^{B}-\alpha_{i_{u}}}{\alpha_{i}^{B}+\alpha_{i_{u}}} \quad(\text { для } i=1,2, \ldots, m) .
\end{gathered}
$$

3 рівнянь (4) та (8)

$$
\alpha=\left(I+\alpha_{0}\right) \beta
$$

при умові, що матриця $\alpha_{0}$ існує та

$$
\left|\alpha_{0}\right| \leq \beta_{0} \leq 1
$$

де

$$
\alpha_{0}=\operatorname{diag}\left[\alpha_{01}, \alpha_{02}, \ldots, \alpha_{0 m}\right] \mathrm{i}\left|\alpha_{0}\right|=\operatorname{diag}\left[\left|\alpha_{01}\right|,\left|\alpha_{02}\right|, \ldots,\left|\alpha_{0 m}\right|\right] \text {. }
$$

Для отримання робастного регулятора скористаємося такою моделлю

$$
x_{e}(t+1, k)=x_{e}(t, k)+e(t, k)=x_{e}(t, k)+y_{r}(t)-y(t, k)=x_{e}(t, k)+y_{r}(t)-C x(t, k),
$$

де $x_{e}(0, k)=0$ i $x_{e}(t, k)$ - інтеграл похибки керування.

Комбінація моделей (11) та (5) формує розширену модель

$$
\mathrm{X}_{1}(t+1, k)=A_{1} X_{1}(t, k)+B_{1} \alpha u(t, k)+W_{1}(t, k),
$$


де

$$
\mathrm{X}_{1}(t+k)=\left[\begin{array}{c}
x(t, k) \\
x_{e}(t, k)
\end{array}\right]
$$

та

$$
A_{1}=\left[\begin{array}{cc}
A & 0 \\
-C & I
\end{array}\right], B_{1}=\left[\begin{array}{c}
B \\
0
\end{array}\right], W_{1}(t, k)=\left[\begin{array}{l}
w(t, k) \\
y_{r}(t)
\end{array}\right] .
$$

Введемо регулятор із зворотним зв'язком за станом

де

$$
\begin{aligned}
u(t, k) & =K_{1} X_{1}(t, k)=K_{11} x(t, k)+K_{12} x_{e}(t, k), \\
K_{1} & =\left[\begin{array}{ll}
K_{11} & K_{12}
\end{array}\right] \in \mathbb{R}^{m \times(n+l)} .
\end{aligned}
$$

Тоді замкнена система керування описується рівнянням

$$
\mathrm{X}_{1}(t+1, k)=\left(A_{1}+B_{1} \alpha K_{1}\right) X_{1}(t, k)+W_{1}(t, k) .
$$

Для синтезу ТВСС-керування згідно [17] потрібно розв’язати матричну нерівність

$$
\left[\begin{array}{ccccc}
-\Omega & \Omega A_{1}^{T}+Y^{T} \beta B_{1}^{T} & \Omega^{T} \beta & \Omega & 0 \\
* & -\Omega+\varepsilon B_{1} \beta_{0}^{2} B_{1}^{T} & 0 & 0 & \mathrm{I} \\
* & * & -\varepsilon I & 0 & 0 \\
* & * & * & -\gamma I & 0 \\
* & * & * & * & -\gamma
\end{array}\right]<0
$$

при умові, що існують додатно визначена матриця $\Omega \in \mathbb{R}^{(n+l) \times(\mathrm{n}+l)}$, матриця $Y \in \mathbb{R}^{m \times(\mathrm{n}+l)}$ та скалярні величини $\varepsilon>0$ і $\gamma>0$. Тоді коефіцієнт зворотного зв'язку системи керування (15) визначається як

$$
K_{1}=Y \Omega^{-1} \text {. }
$$

Відмовостійка система керування циклічними процесами (ВСЦП-керування)

Для циклічного процесу формування вуглецевих виробів, який описується рівнянням (1) запишемо алгоритм керування з ітеративним навчанням (КІН-алгоритм):

$$
u(t, k)=u(t, k-1)+r(t, k) \text { (для } u(t, 0)=0, t=0,1,2, \ldots T),
$$

де $u(t, 0)$ - початкове керування; $r(t, \mathrm{k}) \in \mathbb{R}^{m}$ - функція коригування керування. Задачею синтезу КІНалгоритму є визначення функції коригування $r(t, \mathrm{k})$ такої, щоб $y(t, \mathrm{k})$ відслідковував $y_{r}(t, \mathrm{k})$.

Визначимо

$$
\begin{aligned}
& \delta_{t}(f(t, k))=f(t, k)-f(t-1, k), \\
& \delta_{k}(f(t, k))=f(t, k)-f(t, k-1) .
\end{aligned}
$$

Використовуючи вирази (1), (19) та (6), дістаємо

$$
\begin{aligned}
& \delta_{k}(x(t+1, k))=A \delta_{k}(x(t, k))+B \alpha r(t, k)+\delta_{k}(w(t, k)), \\
& e(t+1, k)=e(t+1, k-1)-C \delta_{k}(x(t+1, k))= \\
& =e(t+1, k-1)-C A \delta_{k}(x(t, k))-C B \alpha r(t, k)+C \delta_{k}(w(t, k)) .
\end{aligned}
$$

Дані рівняння , а також (11) формують розширену модель

$$
\left\{\begin{array}{l}
X_{2}(t+1, k)=A_{21} X_{2}(t, k)+A_{22} X_{2}(t+1, k-1)+B_{2} \alpha r(t, k)+C_{2} \delta_{k}(w(t, k)) \\
Z(t, k)=e(t, k)=G X_{2}(t, k)
\end{array}\right\}
$$

де 


$$
\begin{aligned}
& X_{2}(t, k)=\left[\begin{array}{c}
\delta_{k}(x(t, k)) \\
e(t, k) \\
x_{e}(t, k)
\end{array}\right] \\
& A_{21}=\left[\begin{array}{ccc}
A & 0 & 0 \\
-C A & 0 & 0 \\
0 & I & I
\end{array}\right] \\
& A_{22}=\left[\begin{array}{lll}
0 & 0 & 0 \\
0 & I & 0 \\
0 & 0 & 0
\end{array}\right] \\
& B_{2}=\left[\begin{array}{c}
B \\
-C B \\
0
\end{array}\right] \\
& \mathrm{C}_{2}=\left[\begin{array}{l}
I \\
C \\
0
\end{array}\right], \\
& G=\left[\begin{array}{lll}
0 & I & 0
\end{array}\right]
\end{aligned}
$$

Модель (23) - типова 2D-модель з невідомим збуренням. Враховуючи, що дана модель описує динаміку похибки керування аналогічно (5), їі можна вважати 2D-моделлю похибки керування системи (5). Отже, зрозуміло, що синтез функції коригування $r(t, \mathrm{k})$ для системи (5) означає синтез ВСЦП-керування для 2Dмоделі похибки (23).

Синтезуємо закон керування у вигляді

$$
\begin{aligned}
& r(t, k)=K_{2}\left[\begin{array}{l}
X_{2}(t, k) \\
X_{2}(t+1, k-1)
\end{array}\right]=\left[\begin{array}{ll}
K_{21} & K_{22}
\end{array}\right]\left[\begin{array}{l}
X_{2}(t, k) \\
X_{2}(t+1, k-1)
\end{array}\right]= \\
& =K_{21} X_{2}(t, k)+K_{22} X_{2}(t+1, k-1) .
\end{aligned}
$$

Тоді замкнена 2-вимірна система математично описується так

$$
\left\{\begin{array}{l}
X_{2}(t+1, k)=\left(A_{21}+B_{2} \alpha K_{21}\right) X_{2}(t, k)+\left(A_{22}+B_{2} \alpha K_{22}\right) X_{2}(t+1, k-1)+C_{2} \delta_{k}(w(t, k)) \\
Z(t, k) \hat{=}(t, k)=G X_{2}(\mathrm{t}, k)
\end{array}\right\}
$$

Стан системи (27) змінюється вздовж двох вісей - $T$ - вісь та $K$ - вісь. Зазвичай граничні умови для 2вимірної системи задаються у двох напрямах:

$$
\left\{\begin{array}{ll}
X_{2}(t, 0)=X_{2}^{t, 0} & (\text { для } t=1,2, \ldots) \\
X_{2}(0, k)=X_{2}^{0, k} & (\text { для } k=1,2, \ldots)
\end{array}\right\},
$$

де $X_{2}^{t, 0}$ - обмеження у $K$ - напрямку та $X_{2}^{0, k}$ - обмеження у $T$ - напрямку.

Структурна схема замкненої системи керування показана на рис.1. Точковою лінією позначений інформаційний потік, що надходить 3 попереднього циклу роботи. Неперервними лініями умовно показані потоки інформації зворотного зв'язку реального часу.

Дану структурну схему можна розглядати з двох точок зору - по перше, як 2-вимірну систему, по - друге, як циклічний процес. 3 першої точки зору це система із зворотним зв'язком за двома змінними стану, яка складається з 2-вимірного об'єкту керування та регулятора із зворотним зв'язком за двома змінними стану, які обведені на рис.1 пунктирною лінією. 
3 точки зору циклічного процесу система складається із об’єкта керування (1) (ОК) та ВСЦП-керування (19), що показано на рис.1 суцільною лінією.

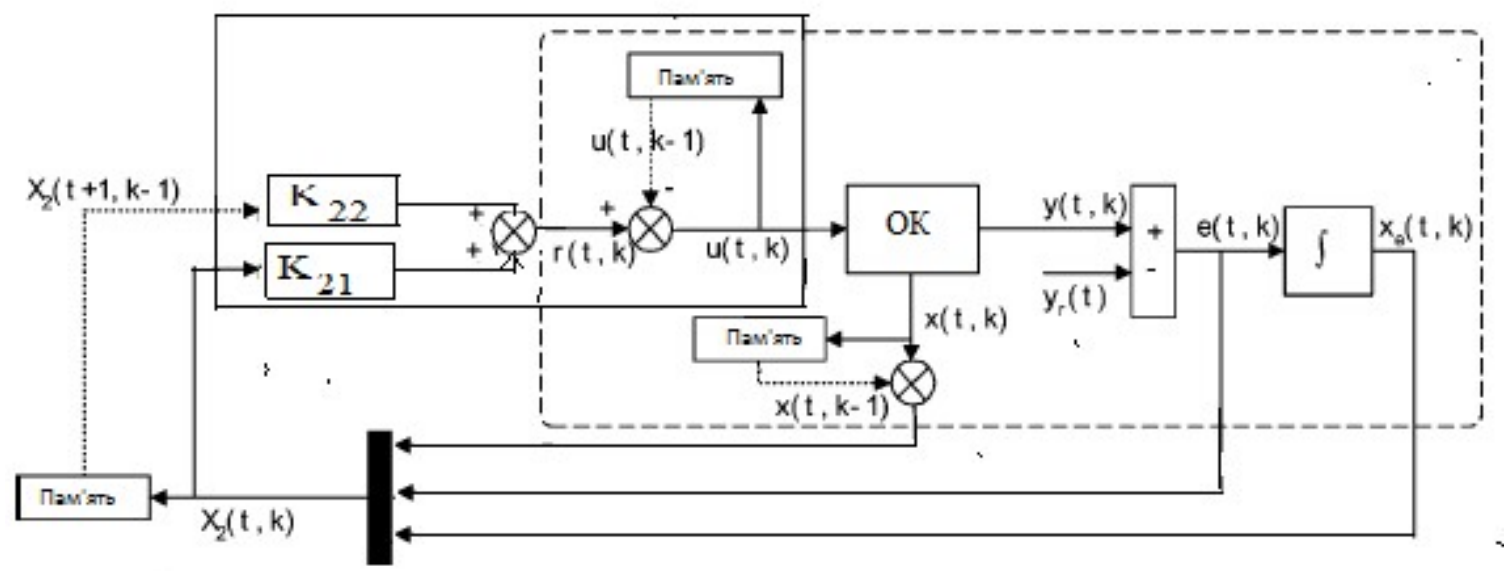

Рис. 1 - Структурна схема замкненої системи керування

3 урахуванням виразів (19) та (26) ВСЦП-керування представляється у такому вигляді

$$
u(t, k)=u_{l}(t, k)+u_{r}(t, k),
$$

де $u_{l}(t, k)=u(t, k-1)+K_{22} X_{2}(t+1, k-1)$ відповідає керуванню 3 ітеративним навчанням, що покращує якість роботи системи від циклу до циклу, та $u_{r}(t, k)=K_{21} X_{2}(t, k)$, яке забезпечує керування із зворотнім зв'язком на протязі поточного циклу роботи. [18]

Синтез системи керування здійснюється шляхом розв'язання системи лінійних матричних нерівностей

$$
\begin{gathered}
{\left[\begin{array}{ccccc}
-S_{1} & 0 & \Omega A_{21}^{T}+Y_{1}^{T} \beta B_{2}^{T} & Y_{1}^{T} \beta \\
* & -S_{2} & \Omega A_{22}^{T}+Y_{2}^{T} \beta B_{2}^{T} & Y_{2}^{T} \beta \\
* & * & -\Omega+\varepsilon B_{2} \beta_{0}^{2} B_{2}^{T} & 0 & 0 \\
* & * & * & & -\varepsilon I
\end{array}\right]<0,} \\
{\left[\begin{array}{cccccc}
-S_{1} & 0 & \Omega A_{21}^{T}+Y_{1}^{T} \beta B_{2}^{T} & Y_{1}^{T} \beta & \Omega G^{T} & 0 \\
* & -S_{2} & \Omega A_{22}^{T}+Y_{2}^{T} \beta B_{2}^{T} & Y_{2}^{T} \beta & 0 & 0 \\
* & * & -\Omega+\varepsilon B_{2} \beta_{0}^{2} B_{2}^{T} & 0 & 0 & C_{2} \\
* & * & * & -\varepsilon I & 0 & 0 \\
* & * & * & * & -\gamma I & 0 \\
* & * & * & * & * & -\gamma I
\end{array}\right]<0,}
\end{gathered}
$$

якщо для даних скалярних величин $\lambda_{1}, \lambda_{2}>1$ існують додатно визначені матриці $\Omega, \mathrm{S}_{1}, \mathrm{~S}_{2} \in \mathbb{R}^{(n+2 l) \times(\mathrm{n}+2 l)}$ , матриці $Y_{1}, \mathrm{Y}_{2} \in \mathbb{R}^{m \times(\mathrm{n}+2 l)}$ та скаляри $\varepsilon, \gamma>0$.

Тоді коефіцієнти рівняння (26) визначаються таким чином

$$
K_{21}=Y_{1} \Omega^{-1}, K_{22}=Y_{2} \Omega^{-1} .
$$

Висновки. На основі об'єднання методу керування з ітеративним навчанням та методу керування, який враховує несправності регулювальних органів, синтезований метод побудови відмовостійкої системи керування циклічним процесом формування вуглецевих виробів, що забезпечує прийнятне функціонування об’єкту керування у нештатних умовах. 
Синтез системи керування здійснюється шляхом розв'язання системи лінійних матричних нерівностей програмними засобами MATLAB.

Перспективи подальших досліджень. У подальшому необхідно розглянути питання оптимальних налаштувань запропонованої системи керування та дослідити її ефективність у порівнянні $з$ традиційними відмовостійкими системами для нециклічних процесів.

\section{Список використаної літератури}

1. Жученко О.А., Коротинський А.П., Хібеба М.Г. Математичне моделювання енергоємних технологічних процесів вуглеграфітового виробництва [текст] : монографія. -К.:КПІ ім. Ігоря Сікорського, 2019. - 344 с.:іл. - 300 прим.

2. Карвацький А. Я. Теоретичні та експериментальні дослідження теплоелектричного та механічного стану високотемпературних агрегатів [Текст] : моногр. / А. Я. Карвацький, С. М. Панов, С. В. Кутузов та ін. К.: НТУУ «КПІ», 2012. - 352 с.: іл.

3. Хібеба, М. Г. Автоматизація процесу керування формуванням вуглецевих виробів : дис. ... д-ра філософії : 151- автоматизація та комп’ютерно-інтегровані технології / Хібеба Микола Григорович. - Київ, 2020. - 163 с.

4. Санников А. К. Производство електродной продукции [Текст]/ А. К. Санников, А. Б. Сомов, В. В. Ключников и др. - М.: Металлургия, 1985. - 129 с. - Библиогр.: 21 назв. - 1230 экз. УДК 621.3.035.2

5. Чалых Е. Ф. Оборудование електродных заводов : учеб. Пособие [для вузов] / Е. Ф. Чалых. - М. : Металлургия, 1990. - 238 с.

6. Шулепов С. В. Физика углеграфитовых материалов [Текст]/ С. В. Шулепов. - М-во просвещения РСФСР. - Челябинск : ЧГПИ, 1968. - 342 с. : граф., табл. ; 22 см. - Библиогр.: с. 319-339 (844 назв.). УДК 661.672.

7. Zhou, D. H.; Frank, P. M. Fault diagnosis and fault tolerant control. IEEE Trans. Aerosp. Electron. Syst. 1998, 34 (2), 420-427.

8. Li, L.; Zhou, D. Fast and robust fault diagnosis for a class of nonlinear systems: detectability analysis. Comput. Chem. Eng. 2004, 28, 2635-2646.

9. Zhang, X.; Parisini, T.; Polycarpou, M. M. Adaptive fault-tolerant control of nonlinear uncertain systems: an information-based diagnostic approach. IEEE Trans. Autom. Control 2004, 49 (8), 1259-1274.

10. Yang, G.-H.; Wang, J. L.; Soh, Y. C. Reliable H¥ controller design for linear systems. Automatica 2001, 37, 717-725.

11. Yang, Y.; Yang, G.-H.; Soh, Y. C. Reliable control of discretetime systems with actuator failure. IEE Proc.-D: Control Theory Appl. 2000, 147 (4), 428-432.

12. Wu, H.-N.; Zhang, H.-Y. Reliable mixed L2/H fuzzy static output feedback control for nonlinear systems with sensor faults. Automatica 2005, 41, 1925-1932.

13. Scenna, N. J. Some aspects of fault diagnosis in batch processes. Reliab. Eng. Syst. Saf. 2000, 70, 95-110.

14. Gao, F.; Yang, Y.; Shao, C. Robust iterative learning control with applications to injection molding process. Chem. Eng. Sci. 2001, 56, 7025-7034.

15. Gorinevsky, D. Loop shaping for iterative control of batch processes. IEEE Control Syst. Mag. 2002, 22 (6), 55-65.

16. Xiong, Z.; Zhang, J. Product quality trajectory tracking in batch processes using iterative learning control based time-varying perturbation models. Ind. Eng. Chem. Res. 2003, 42 (26), 6802-6814.

17. Yu, L. An LMI approach to reliable guaranteed cost control of discrete-time systems with actuator failure. Appl. Math. Comput. 2005, 162, 1325-1331.

18. Y.Shen, L.Wang, J.Yu, R.Zhang, F.Gao. A hybrid 2D fault-tolerant controller design for multi-phase batch processes with time delay. Journal of Process Control 69 (2018) 138-157.

\section{Liudmyla Zhuchenko}

\section{FAULT-TOLERANT CONTROL SYSTEM FOR THE FORMATION OF CARBON PRODUCTS}

The production of carbon products is largely resource- and energy-intensive. That is why increasing the efficiency of this production is an urgent scientific and practical task, especially in modern conditions of constant growth of energy costs. An effective way to solve this problem is to create a modern process control system, taking into account possible failures of system components.

A method for the synthesis of a fault-tolerant control system for the cyclic formation of carbon products has been developed, which takes into account control errors that are caused by malfunctions of controllers under conditions of unknown disturbances. According to the cyclic nature of the technological process under consideration, a control 
method with iterative learning was used in the synthesis of the control system. This method considers cyclic processes based on a two-dimensional model (2D model).

The proposed control algorithm ensures the convergence of the control process with the task both in time and in each work cycle in order to promote the required quality of control even in the event of unknown disturbances and errors in the performance of controllers. The synthesis of the control system is based on the solution of a system of linear matrix inequalities.

Based on the combination of a control method with iterative learning and a control method that takes into account failures in controllers, a method of constructing a fault-tolerant control system for the cyclic formation of carbon products has been synthesized to ensure acceptable operation of the control object in abnormal conditions.

The control system has been synthesized by solving a system of linear matrix inequalities with the MATLAB software. In the future, it is necessary to consider optimal settings of the proposed control system and examine its effectiveness in comparison with conventional fault-tolerant systems for non-cyclic processes.

Keywords: fault-tolerant system, carbon products, control, control algorithm, control quality.

\section{References}

1. Zhuchenko O.A., Korotinsky A.P., Khibeba M.G (2019). Matematychne modeliuvannia enerhoiemnykh tekhnolohichnykh protsesiv vuhlehrafitovoho vyrobnytstva [Mathematical modeling of energy-intensive technological processes of carbon graphite production] : monohrafiia. Kyiv. $-344 \mathrm{p}$.

2. Karvatskyi A. Ya. (2012). Teoretychni ta eksperymentalni doslidzhennia teploelektrychnoho ta mekhanichnoho stanu vysokotemperaturnykh ahrehativ [Theoretical and experimental studies of the thermoelectric and mechanical state of high-temperature units] / A. Ya. Karvatskyi, Ye. M. Panov, S. V. Kutuzov - K.: NTUU «PI», - $352 \mathrm{p}$.

3. Khibeba, M. H. (2020) Avtomatyzatsiia protsesu keruvannia formuvanniam vuhletsevykh vyrobiv [Automation of the process of controlling the formation of carbon products] : dys. ... d-ra filosofii - Kyiv, $-163 \mathrm{p}$.

4. Sannykov A. K. (1985) Proyzvodstvo elektrodnoi produktsyy [Manufacture of electrodes]/ A. K. Sannykov, A. B. Somov, V. V. Kliuchnykov - M.: Metallurhyia,. - 129 p.

5. Chalykh E. F. (1990). Oborudovanye elektrodnykh zavodov. [equipment for electrode plants] / E. F. Chalykh. - M. : Metallurhyia. - 238 p.

6. Shulepov S. V. (1968) Fyzyka uhlehrafytovykh materyalov [Physics of carbon-graphite materials]/ S. V. Shulepov. - M-vo prosveshchenyia RSFSR. - Cheliabynsk, - 342 p..

7. Zhou, D. H.; Frank, P. M. Fault diagnosis and fault tolerant control. IEEE Trans. Aerosp. Electron. Syst. 1998, 34 (2), 420-427.

8. Li, L.; Zhou, D. Fast and robust fault diagnosis for a class of nonlinear systems: detectability analysis. Comput. Chem. Eng. 2004, 28, 2635-2646.

9. Zhang, X.; Parisini, T.; Polycarpou, M. M. Adaptive fault-tolerant control of nonlinear uncertain systems: an information-based diagnostic approach. IEEE Trans. Autom. Control 2004, 49 (8), 1259-1274.

10. Yang, G.-H.; Wang, J. L.; Soh, Y. C. Reliable H¥ controller design for linear systems. Automatica 2001, 37, 717-725.

11. Yang, Y.; Yang, G.-H.; Soh, Y. C. Reliable control of discretetime systems with actuator failure. IEE Proc.-D: Control Theory Appl. 2000, 147 (4), 428-432.

12. Wu, H.-N.; Zhang, H.-Y. Reliable mixed L2/H fuzzy static output feedback control for nonlinear systems with sensor faults. Automatica 2005, 41, 1925-1932.

13. Scenna, N. J. Some aspects of fault diagnosis in batch processes. Reliab. Eng. Syst. Saf. 2000, 70, 95-110.

14. Gao, F.; Yang, Y.; Shao, C. Robust iterative learning control with applications to injection molding process. Chem. Eng. Sci. 2001, 56, 7025-7034.

15. Gorinevsky, D. Loop shaping for iterative control of batch processes. IEEE Control Syst. Mag. 2002, 22 (6), 55-65.

16. Xiong, Z.; Zhang, J. Product quality trajectory tracking in batch processes using iterative learning control based time-varying perturbation models. Ind. Eng. Chem. Res. 2003, 42 (26), 6802-6814.

17. Yu, L. An LMI approach to reliable guaranteed cost control of discrete-time systems with actuator failure. Appl. Math. Comput. 2005, 162, 1325-1331.

18. Y.Shen, L.Wang, J.Yu, R.Zhang, F.Gao. A hybrid 2D fault-tolerant controller design for multi-phase batch processes with time delay. Journal of Proctss Control 69 (2018) 138-157. 